Journal of Social and Development Sciences

Vol. 6, No. 1, pp. 39-45, March 2015 (ISSN 2221-1152)

\title{
Potential of Slum Tourism in Urban Ghana: A Case Study of Old Fadama (Sodom and Gomorra) Slum in Accra
}

\author{
*Franklin Komla Aseye, Bormann, Matthew Opoku, Agyeman-Duah \\ Ho Polytechnic, Ho, Ghana \\ *franklinbormann@yahoo.com
}

\begin{abstract}
The paper assessed the state of tourism in the slum community of Old Fadama (Sodom and Gomorra) in Accra, Ghana. It goes without saying that Old Fadama vehemently referred to as Sodom and Gomorra is a full embodiment of the characteristics of informal settlements better known as slums. Semi structured questionnaires were administered randomly to 250 dwellers of Sodom and Gomorra. In-depth interviews were purposively held with officials of local Travel and Tour Firms and the regional Office of the National Tourism Authority. Data was analyzed descriptively and thematically. Observing residents' life style and photograph taking were found as the main tourist activities. Tourism was promoted through security consciousness of residents. Low involvement of residents in tourism affairs/businesses were the major drawbacks to tourism development in the slum. Residents needs to be sensitized to take advantage of their living conditions to establish tourism businesses in the short-term to empower them move to more 'formal' settlements of Accra in the near future to decelerate the growth of the notorious slum in Ghana's capital city.
\end{abstract}

Keywords: Slum, Tourism, Old Fadama, Sodom and Gomorra, Urban Ghana

\section{Introduction}

Slums are mostly found in urban areas because people tend to move to the city in search of better life. According to Mowforth (2008), people are living in an increasingly urbanized world and this is likely to accelerate rather than reverse the growth of slums. Global urban transition is only at mid-point with projections showing that over the next 25 years the world's urban population is set to increase to 4.9 billion people by 2030, roughly $60 \%$ of the world's total population (UNDESA, 2006). Moreover, the most significant growth is projected to occur in less developed regions with sustained and rapid increases culminating in 3.9 million urban dwellers in these regions by 2030 (UNDESA, 2006). It is the nature of this growth that is of great significance with a rapid increase in the number of the poor, the majority of whom are likely to be concentrated into city slums (UNHABITAT, 2003). Accumulation of people in a small area leads to socioeconomic challenges including very low levels of income and lack of proper sanitation. Such challenges and the creative activities of slum residents in the effort of overcoming their problems has in recent years proved attractive and people have been attracted to touring the slums. Slum tourism was established in developing countries in the mid 1990s (Rolfers, 2009). The essential part of this tourism is visiting the most disadvantaged parts of the cities called slums. It is mainly organized in form of the guided tours. Slum tours are offered in a relatively large scale in the South Africa cities such as Johannesburg and Cape Town, the Indian metropolises of Calcutta, Mumbai and Delhi as well as Rio de Janeiro in Brazil. Those involved in these tours are primarily international tourists. Indeed, the number of slum tourists is constantly increasing. It is estimated that 40,000 tourists visit Rio de Janeiro slums each year, while in Cape Town the estimated figures are around 300,000 (Rolfers, 2009). Tour firms have therefore realized that slums are an attraction and are organizing slum tours (Armstrong, 2005) which are slowly becoming a common phenomenon in the cities of the developing countries. For instance, slum tourism is well established in Brazil where it started in 1992 in a shanty town in Rio de Janeiro (Funke, 2008). It then spread to the rest of the world including Africa, particularly in South Africa where it is well established. Today it has spread to other African cities, including Sodom and Gomorra in Accra, Ghana. Sodom and Gomorra is the most visited slum in Ghana. This idea of slum tourism is a means of creating awareness of the plight of the urban poor in developing societies to both foreign and domestic tourists. According to Mowforth (2008), the intention is to eradicate slums in developing societies using tourism business and reducing poverty by engaging the poor to participate more 
effectively in tourism development and increasing net benefits from tourism as a short term measure to the slum community.

Ghana markets herself as a tourist destination through the Ghana Tourism Authority (GTA). Currently, Ghana's major tourism products include wildlife, sandy beaches, cultural attractions and the numerous scenic geomorphologic formations. According to the Institute of Social Statistical and Economic Research (ISSER) (2008), various tourism products need to be developed for the tourism industry to grow and enhance customer satisfaction. In addition, Lea (1988) states that lack of diversity encourages mass tourism mainly to natural areas that receive a huge number of tourists at any one given time. This in the long run stresses natural areas and negatively affects the environment. Slum tourism targets the disadvantaged communities and therefore it is a good form of Pro-Poor Tourism (PPT). PPT aims at unlocking opportunities for the poor for economic gain, livelihood benefits, or participation in decision-making (Ashley et al., 2001) in which slum tourism has lot of potential. Slum tourism can also help in shifting focus from environment and wildlife-based tourism to poverty-reducing tourism which will have more benefits to the poor and less impact to the environment. What is the status of tourism in Sodom and Gomorra slum? What is the nature of participation of the dwellers in tourism development? Does tourism have any socio-economic potential in the slum?

\section{Literature Review}

Slums as Tourist Attraction: Tourists visit destinations because they are attractive and offer different experiences. Tourism attractions are divided into two; man-made and natural (Cooper et al., 2005). The natural attractions include the landscape, climate, vegetation, forests and wildlife. Man-made attractions are composed of the product of history, culture, artificially-created entertainment and events. According to Rolfers (2009), the main tourism motivation to the city slums includes country's culture and the residents' living conditions. Children also play important role in many tours because they dance and sing to the tourists during visits. Children frequently surround or follow the visitors who use these situations as opportunities to take photographs. Some of the residents expose their poverty to the tourists so as to offer possibility to have their situations improved through donations to their socio-economic activities.

Challenges of Slums: Dwellers in slum communities are mostly illiterate or semi-literate, majority have primary education only (Funke, 2008). Access to jobs is a major problem and leads to social ills such as alcoholism, drug abuse and crime. Slums lack clean drinking water, proper plumbing, access to health care facilities, poor electrification and other public services including schools (Farouk \& Owusu, 2012). According to a report of UN- HABITAT (2008), water and sanitation are key problems in Slums. The report acknowledges that over the years, Slums have received significant investment (both physical and financial) to alleviate the poor conditions that exist with respect to water, sanitation and health but no significant impact has been made. Other issues reflected in the report include little effort that has been made to link sanitation to income generation and livelihood for Slum dwellers. The vast majority of water and sanitation initiatives have not been integrated. Although there are few studies assessing the contribution of tourism in slums, slum tourism has provided slum communities with opportunities to upgrade their living conditions. Slum tourism therefore has the potential to improve the socio economic status of slum communities.

Benefits of Slum Tourism: Tourism is known to significantly contribute to development, both directly and indirectly. Traditional tourism heavily relies on natural attractions which with time get negatively affected (Singh, 2004). For this reason new forms of tourism are now being developed. Slum tourism is one such development. Modern tourism targets improving socio economic situations of the local communities, an aspect that makes it pro-poor. According to Cooper et al. (2005), new tourism is a force capable of dramatically improving socio-economic well being of the communities across the globe. For instance, propoor tourism focuses on poverty reduction. Pro-poor forms of tourism possess three elements as stated by Cooper et al. (2005). Firstly it accelerates growth and development of local areas. Secondly, it improves the distribution of income and wealth, and thirdly, it accelerates social development. According to David (2005), any type of tourism that aims at generating benefits for the poor and to unlock the opportunities for the poor is pro-poor. According to Ashley et al. (2001) Pro-Poor tourism seeks to improve the economy for poor people. It enhances linkages between tourism businesses and poor people, so that poor people are able to participate more effectively in tourism development. Benefits of pro-poor tourism are diverse. According to 
Cooper et al. (2005) they include making destinations safer, reduce possible hostile attitudes from the local community and making the destination more attractive by reducing the number of shanty towns and beggars. Slum tourism has great potential to offer these benefits. Although not being specific to slum tourism, Singh (2004) divides benefits of pro-poor tourism to poor people into two broad categories, namely economic and non-economic. The first category includes job opportunities and small enterprise opportunities. The second one includes infrastructure and healthcare. These create opportunities for economic activities to slum communities. According to Michael (2007), the poor must have access to economic activities which they can use to change their destiny. They should be empowered to strengthen their participation in decision making. Pro-Poor tourism therefore, can facilitate the growth of small enterprises in the slums and this will encourage slum residents to actively participate in economic activities.

Profile of Study Area and Research Methods: The study was carried out in Sodom and Gomorra slum southwest of the Central Business District (CDB) of Accra, Ghana. It has an approximate area of three (3) Kilometers square and is considered the largest slum in Ghana. It is a lowland and subject to frequent flooding. It stretches from the Korle Lagoon to the east and Lartebiokoshie residential area to the west. It has its beginnings as a migrant's settlement. It has a mix of commercial and residential temporary building units. The settlement is mainly built of timber cut offs and galvanized corrugated iron. Others live in Shacks and kiosks that are exposed to fire out breaks (Grant, 2006). The average size of residential houses (shacks) in this area is $12 \mathrm{ft} x 12 \mathrm{ft}$. These shacks often house up to 8 or more, many sleeping on the floor. Sodom and Gomorra has a lorry station at Agbogbloshie, but most residents use motorcycles (okada) to reach the city centre. Carjacking, irresponsible driving, and poor traffic law enforcement are chronic issues. The slum is heavily polluted by human refuse, garbage, soot, dust, and other wastes. The slum is contaminated with human and animal excreta, due to the open sewage system and the frequent use of "flying toilets". The lack of sanitation combined with poor nutrition accounts for many disease outbreaks in the slum. The people are mainly Ghanaian with few other West African Nationalities. The original settlers were Muslims from Northern Ghana and they currently constitute about $48 \%$ of the Sodom and Gomorra population. The shack owners are mostly the $\mathrm{Ga}$ people (the major tribe in the Odododiodoo electoral area of Accra Central) and in most cases are absentee landlords. The tenants are natives of different parts of Ghana and West Africa. There are many tensions particularly between landlords and tenants on one hand and dwellers with and without jobs on the other. It is the most densely populated sub-location in Odododiodoo electoral area. The population of Sodom and Gomorra stood at approximately 80,000 in the year 2009 (Housing the Masses, 2010) Businesses are mainly informal with kiosks along internal routes. The Sodom and Gomorra slum provides labor to the surrounding industries and the yam and onion market at Agbogbloshie. They also provide domestic labor to the surrounding residential areas of Korle-bu and Lartebiokorshie residential areas. The women dwellers have petty businesses such as vending cooked food, hawking small items like sweets or work as load carriers (Kayayoo)

\section{Methodology}

Residents of Sodom and Gomorra and representatives of professional Tour Companies in Central Accra were the population of interest. Residents of Sodom and Gomorra were targeted on account of their direct encounter with slum tourist. Tour firms were involved because they are engaged in marketing tourist attractions and/or arrange tours in including slum tours (Armstrong, 2005). Two hundred and fifty (250) residents of Sodom and Gomorra slum were simple randomly sampled for the questionnaire survey. Three (3) employees from Travis, Sedodzifa and Akwaba Travel Agencies were purposively interviewed for the case analysis. A key informant interview was also held with the Chief Executive of the National Tourism Authority, Greater Accra Regional Office.

\section{Result and Discussion}

Tourist Attractions and Activities in Sodom and Gomorra: In order to establish the status of tourism in Sodom and Gomorra, potential tourist attractions in the slum were explored. Residents viewed their usual culture of routine entertainment vis a vis their socio-economic setting as main attraction (magnet) to tourists as shown in Figure 1 below 
Figure 1: Tourist Attractions in Sodom and Gomorra

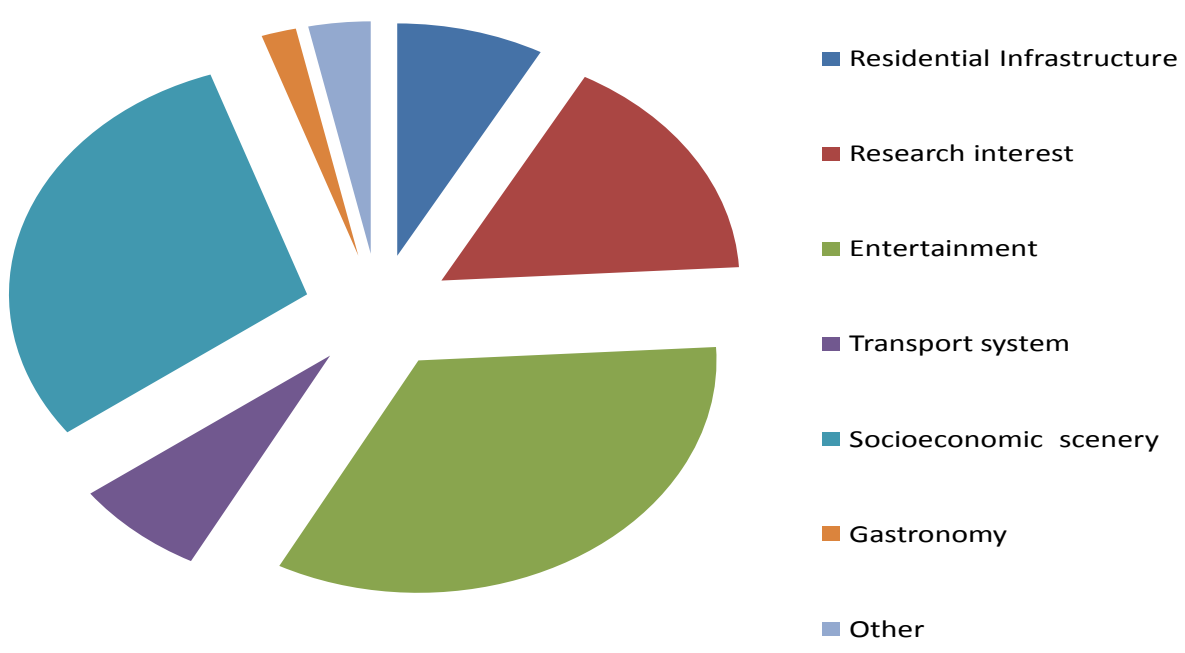

Residents indicated they normally present entertainment in the form of Songs (Dzama) dances (Zibo), drama and cinema. Their socioeconomic setting also provides opportunities to visitors to film or take photographs but with their own express consent. Respondents overwhelmingly (98\%) indicated that tourists are seen at Sodom and Gomorra with almost daily frequency with only $2 \%$ of the respondents of a contrary view. It was observed also that foreigners dominated the patronage of their community and seen in groups with backpacks. Their length of stay was an average of 48 hours but with nights passed at hotels in central Accra. This suggests Sodom and Gomorra as an active tourist destination. According to Cooper et al. (2005), attractions provide the single most important reason for touring a destination and slums are not left out. Tourists once in a destination get involved in various activities. A higher proportion of Sodom and Gomorra residents (90\%) cited observation of their activities and photograph taking as the most popular activities of tourists: Figure 2.

\section{Figure 2: Tourists' Activities in Sodom and Gomorra Slum}

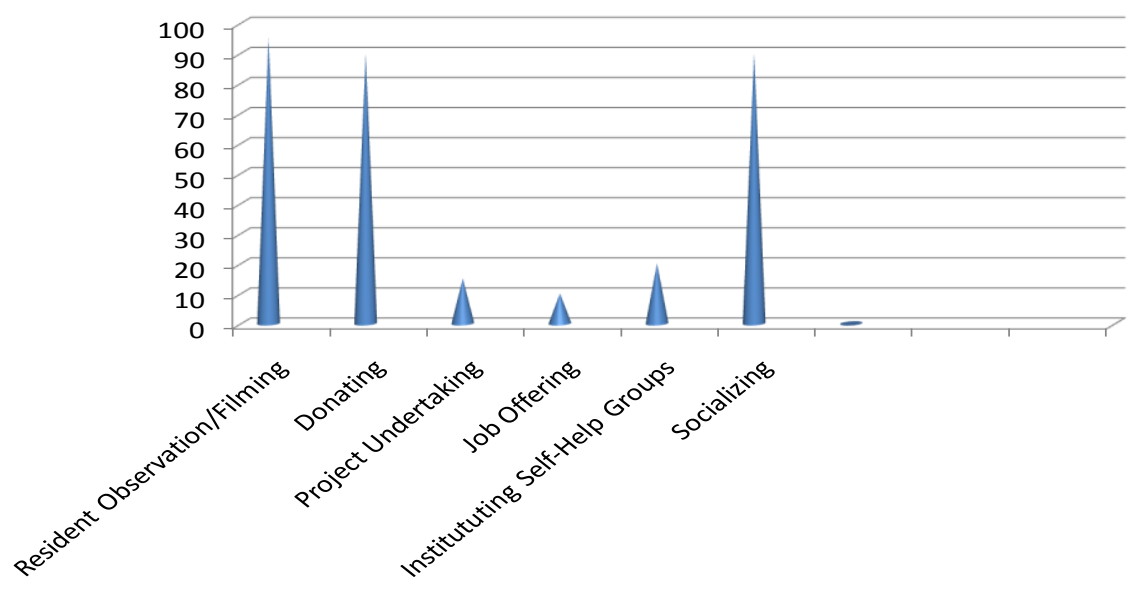

Unlike rural tourism where embarking on development projects and setting up of self-help groups were the leading tourist activities (Bormann, 2011) these activities were less prioritized activities in Sodom and 
Gomorra in Accra. The current finding also conflicts with the Canary Islands Declaration on Tourism in Least Developed Countries (UNLDC III, 2001a) which emphasized tourism development as an avenue to increase participation in the global economy, alleviate poverty and initiate socio-economic development schemes for all people of developing countries.

Resident involvement in tourism development at the slum: With regards to residents' involvement in the tourism activities undertaken in the slum, four (4) main ways were cited: Figure 4, Majority of the respondents (81.6\%) indicated security provision while $42 \%$ claimed they served as slum tour guides.

Figure 3: Participation of Residents in offering tourism services

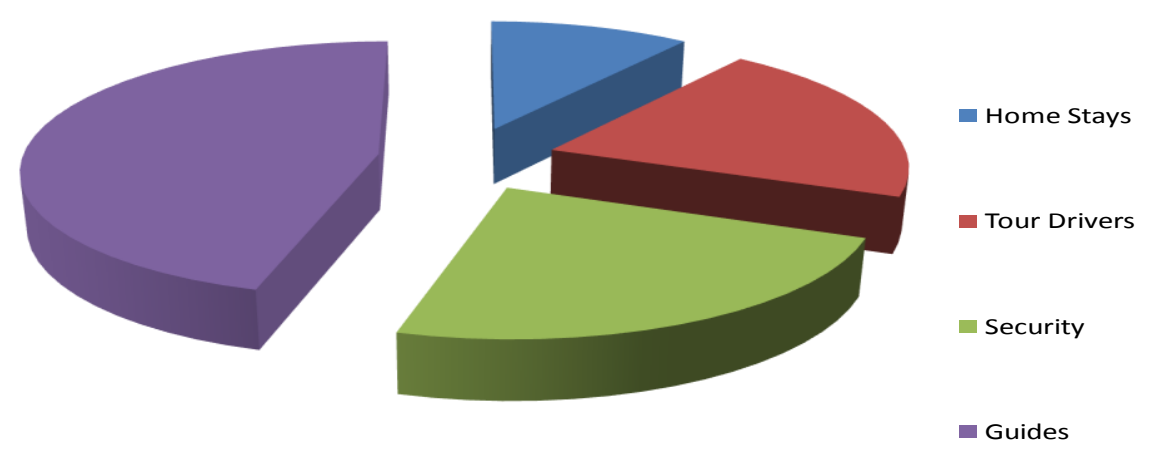

It was clear that residents did not form part of the organization and management of the tours and therefore did not participate in decision making regarding the tourist itinerary. This result conforms to Dweks (2004) analysis which found that most of the tours are actually managed by outsiders whiles residents act as guides. According to Rolfers (2009) a strong involvement of the residents in the tours has to be achieved because the interaction between residents and the tourist is a central aspect which determines the benefits of the residents from the whole tourism exercise. It allows residents to participate in decision making on what should be done which in turn rules out the possibility of residents being forced into humiliation. Rolfers (2009) recommends that communities in slums should be deeply involved in arrangement and offering of slum tours to participate in decision making and should be allowed to take part in management of tour firms to fulfill the needs of the local population. The ability of the local people to take their own decisions related to tourism development, according to their own policies without being manipulated by business people in the tourism sector or multinational companies will concentrate the benefits of the slum tourism to the slum community.

Potential of Tourism in Sodom and Gomorra Slum: Residents of the slum were of the strong view that tourism could bring more positive change to poverty in Sodom and Gomorra. Majority of the dwellers (84\%) responded in favor of slum tourism as being pro-poor. Employees of the tourism firms were of the conviction that slum tourism would create employment, which would in turn generate revenue and boost investment activities in the slum. This rhyme with the response of one of the travel agency representative during an interview: 'When we arrange the tours and call the slum boys to take them round they usually bring tips worth \$ 30 beside the guide charge on a typical lucky day.' They explained that tourism activities presented an opportunity for residents to organize themselves and in the process attract funding for their activities. This implies that slum residents could have opportunity like any other Ghanaian community to benefit from the newly introduced tourism development levy in Ghana whose aim according to the Ghana Tourism Official interviewed is to contribute to poverty reduction through tourism. Community development is a process by which efforts of people are combined with those of public authorities to improve the socio-economic and cultural conditions of communities (Chitere, 1994). It is to integrate communities into the life of the nation and enable them contribute fully to national development. The essential element of this complex is 
participation by the people in efforts to improve their standard of living with as much reliance as possible on their own initiatives (Segbefia, 2009). Having an organized group of entrepreneurs to offer services to the slum tourists would also have other benefits as highlighted in the literature review: the Soweto slum residents came together and formed an association whose members are tour operators, caterers, entertainers and conference organizers and their major work is to ensure that Soweto grows and develops into a major tourist destination in South Africa. It was the view of 56\% of Sodom and Gomorra respondents that their interaction with tourists gave them exposure and encouraged creativity among them.

Figure 4: Views on Pro Poor Potential of Slum Tourism Activities

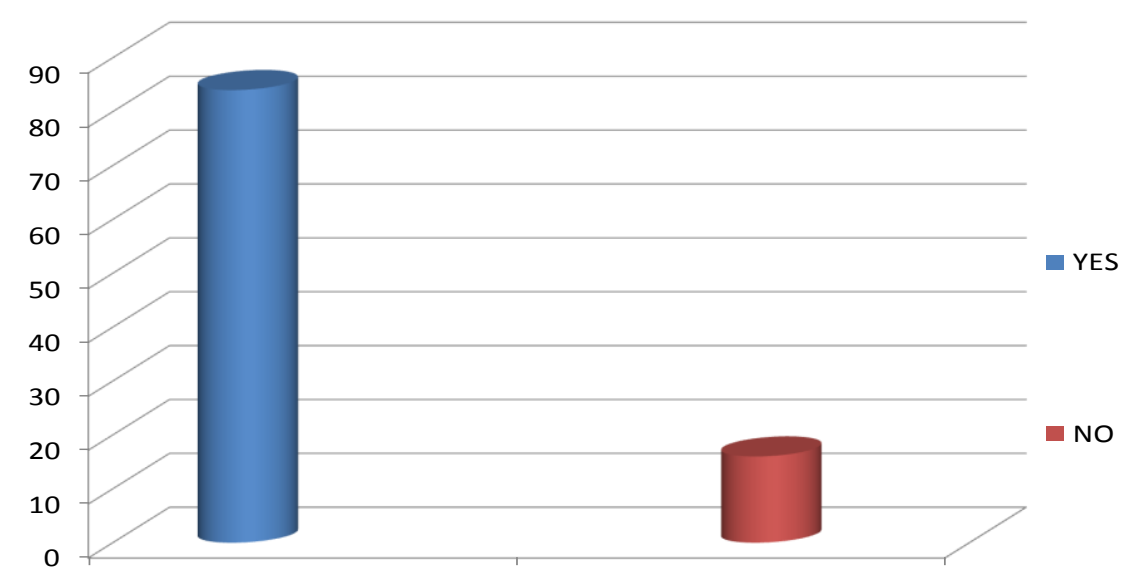

\section{Conclusions and Recommendations}

From the above discussion, it is concluded that Sodom and Gomorra slum in Accra is a tourist destination with observing residents' way of life, making donations and photograph taking as the main tourism activities. Slum tourism did not show potential for urban slum security enhancement, creativity and employment only but engaged residents as slum tour guides and security guards. Slum Tourism is viable in Urban Ghana. Tour companies can do more towards involving slum residents in planning and offering tours to ensure all inclusive slum tours and stakeholders are challenged to develop a policy that specifically addresses slum tourism and to guide stakeholders with a view to streamlining related activities including its awareness campaign. Slum residents may consider merging together and form a formal association to attract significant funding for their involvement in tourism services. Therefore slum tourism can be considered as a strategy for pro-poor growth to decelerate slum community growth in Urban Ghana.

\section{Reference}

Armstrong, M. (2005). Favera tours. Retrieved May 15, 2008, from Rio de Janeiro Tours.

Ashley, C., Roe, D. \& Goodwin, H. (2001). Pro-poor Tourism Strategies: Making Tourism Work for the Poor. London, IIED.

Bormann, F. K. A. (2011). Community-Based Ecotourism and Socio-Economic Empowerment in the Hohoe Municipality of Ghana. (M.Phil Thesis) Department of Geography and Resource Development, University of Ghana, Legon

Cooper, C., Fletcher, J., Fyall, A., Gilbert, D. \& Wanhill, S. (2005). Tourism Principles and Practices. Pearson Education Limited.

David, A. F. (2005). Tourism Ethics. Channel view publishers. driven Enumerations in Blocking Eviction in Old Fadama, Accra. Environment and Urbanization, 47-57.

Farouk, B. R. \& Owusu, M. (2012). If in Doubt Count: the Role of Community- 
Funke, D. (2008). Regional Ethics Bowl Cases. Poverty Tours. Association for Practical and Professional Ethics

Gerosa, V. (2003). Pro-Poor Growth Strategies in Africa. tourism: a viable option for pro-poor growth in Africa? Economics Communication for Africa. Ghana', Urban Forum, 17/1

Grant, R. (2006). Out of place? Global citizens in local spaces: A study of the Informal Settlements in the Korle-Lagoon Environs in Accra,

Housing the Masses. (2010). Enumeration Report for Old Fadama Community, Accra - 2009. Accra

ISSER: The State of the Ghanaian Economy, 2002-2011 Issues: Sections on Tourism, Institute of Statistical Social and Economic Research, University of Ghana, Legon.

Kotler, P. (1994). Marketing Management; Analysis Planning, Implementation and Control. London: Prentice Hall.

Lea, J. (1988). Tourism and Development in the Third World. London, Routledge 11 New Fetter Lane.

Martin, M. \& Munt, I. (2008). Tourism and sustainability. Development Globalization and New Tourism in the Third World. Routledge.

Moot, D. (2011). Faces of Old Fadama. Universal Access to Education Not for All in Ghana. Accra, Ghana: African University College of Communications.

Mowforh, M. (2008). Tourist and Responsibility: Perspectives from Latin America and the Caribean. Routledge.

Rolfers, M. (2009). Township as an Attraction. An Empirical Study of Township Tourism in Cape Town. Universitats verlag Potsdam.

Segbefia, A. Y. (2009). A Study on Handicrafts as a Pro-Poor Tourism Development Strategy in Four Craft Villages in Ashanti Region, Ghana. Unpublished Doctoral Dissertation, University of Ghana, Legon

Singh, G. (2004). New Horizon in Tourism. Strange Experiences and Stranger Practices. CABI Publishing

Third United Nations Conference on the Least Developed Countries. (2001a). The Canary Islands Declaration on Tourism in the LDCs. High Level meeting on Tourism and Development in the Least Developed Countries. Las Palmas, Spain.

UNCTAD (United Nations Commission on Trade and Development) and WTO/OMT. (2001). Tourism in the Least Developed Countries. High level Meeting on Tourism and

Development in LDCs. Gran Canaria, Spain, 26-29 March 2001. Madrid; WTO/OMT.

UN-HABITAT (2008). Tourism and Local Agenda 21 - the role of Local Authorities in Sustainable Tourism. United Nations Publications.

United Nations Economic for Africa. (2003). Economic Report on Africa. Addis Ababa. UNECA. UNLDC III. 